SISTEMA
ELETROANICO
DE REVISTAS
SER I UfPR

\title{
Frederico Carlos Hoehne e o Horto Oswaldo Cruz
}

\section{Frederico Carlo Hoehne and the Horto Oswaldo Cruz}

\author{
Luna Abrano BOCCHI ${ }^{1 *}$, Ermelinda Moutinho PATACA ${ }^{1}$ \\ ${ }^{1}$ Universidade de São Paulo (USP), São Paulo, SP, Brasil. \\ *E-mail de contato: lunabocchi@gmail.com
}

Artigo recebido em 1 de outubro de 2018, versão final aceita em 14 de junho de 2019.

\begin{abstract}
RESUMO: O Instituto Butantan (SP) teve ao longo de sua existência algumas atividades voltadas ao estudo da botânica. O Horto Oswaldo Cruz, criado no local, surgiu em meio às discussões sobre a saúde pública e tinha como objetivo o estudo e o cultivo de plantas tóxicas e medicinais. A iniciativa foi chefiada por Frederico Carlos Hoehne, botânico que se notabilizou pelos estudos na área e pela atuação em instituições governamentais paulistas. Neste artigo, analisamos a atuação de Hoehne quando foi responsável pelo horto entre os anos de 1917 e 1924. O estudo aborda as atividades realizadas no local, procurando entender o cotidiano das práticas científicas a partir dos cultivos e da criação de uma rede de interlocutores. A análise dos relatórios anuais do Instituto Butantan e das publicações de autoria de Hoehne explicita como os objetivos traçados foram traduzidos em ações cotidianas, colocando em destaque os interesses ligados à saúde e aos diversos usos que poderiam ser feitos das espécies cultivadas. Os resultados indicam que as orientações governamentais, ainda que importantes, não foram unicamente consideradas. Os interlocutores do horto botânico, as preferências de Hoehne e os limites impostos pelas condições materiais também influenciaram e ajudaram a delimitar o que foi realizado.
\end{abstract}

Palavras-chave: botânica; Frederico Carlos Hoehne; horto botânico; Instituto Butantan.

ABSTRACT: Over its lifetime, the Butantan Institute (in São Paulo) has developed some activities focusing on the study of botany. Within the Institute, the Oswald Cruz Botanical Garden was created amidst the discussions about public health and focused on the study and cultivation of medicinal and poisonous plants. Botanist Frederico Carlos Hoehne, who led the initiative, was recognized by his studies in the area and by his performance in governmental institutions of São Paulo at the time. In this paper, we analyze Hoehne's performance while he was in charge of the Botanical Garden from 1917 to 1924. This study approaches the activities performed in this institution and aims to understand the routine of scientific practices based on the cultivations and on establishing a network with interlocutors. The analysis of the annual reports produced by the Butantan Institute and Hoehne's publications show how the established objectives were transformed into actions on a daily 
basis, highlighting the interests related to health and the different uses of the cultivated specimens. The results indicate that, although governmental orientations were important, they were not exclusively considered. The interlocutors of the Botanical Garden, Hoehne's preferences and the limits imposed by material conditions influenced and helped to delimit what had been done.

Keywords: botany; Frederico Carlos Hoehne; botanical Garden; Butantan Institute.

\section{Introdução}

A criação de hortos e jardins botânicos no Brasil atendeu a diversos interesses conforme o período, o local em que foram estabelecidos e as pessoas vinculadas às iniciativas. Durante a Primeira República, a aclimatação de plantas e a descoberta de novas espécies já não eram as funções primordiais, como outrora foram quando o território brasileiro se vinculava ao Estado português. Ainda que esses interesses científicos permanecessem, estavam ligados a outras demandas de um crescente espaço urbano e às ideias de progresso e higiene em voga.

Em São Paulo, Frederico Carlos Hoehne foi uma das vozes favoráveis ao estabelecimento de locais voltados ao estudo da botânica. Para ele, a destruição das matas, a cultura dos campos e a exploração do solo eram responsáveis pelo desaparecimento de inúmeras plantas e animais úteis, razão pela qual defendia a necessidade de hortos botânicos destinados ao cultivo e ao estudo da flora indígena por meio de culturas racionais e científicas (Hoehne, 1925a, p. 36). Essa preocupação não era exclusiva de Hoehne e, no final do século XIX e início do XX, outros estudiosos tiveram destaque. Há, entretanto, menos pesquisas sobre a instalação e desenvolvimento de hortos e jardins botânicos no período. Ainda que nos estudos recentes realizados por historiadores, sociólogos e filósofos da ciência, Raj (2007, p. 8) identifique que uma das principais realizações tenha sido "localizar a criação de conhecimento em contextos precisos de tempo e lugar - tipicamente em espaços fechados como laboratórios, observatórios, museus, gabinetes de curiosidades, jardins botânicos e zoológicos, bibliotecas e hospitais" ${ }^{\prime}$ - as pesquisas brasileiras incidiram sobre esses locais de maneira desigual.

Na dissertação sobre o Jardim Botânico de São José, Sanjad (2001, p. 8) chamou a atenção para a carência de estudos sobre os jardins botânicos brasileiros, se comparado com os dedicados a outras instituições, tais como os museus de história natural. Já Silva (2016, p. 17-18), ao se referir à história do paisagismo, ponderou que são recentes as pesquisas sistemáticas sobre os jardins públicos brasileiros, produzidas especialmente por arquitetos, por alguns historiadores e historiadores da arte, motivo pelo qual aponta o predomínio de abordagens ligadas ao projeto paisagístico, estilos artísticos, aspectos construtivos e materiais. Marins \& Schpun (2017, p. 10) reforçam o argumento ao indicarem que os parques e jardins urbanos são "um objeto particular-

\footnotetext{
${ }^{1}$ Tradução livre de: "locating knowledge making in precise contexts of time and place - typically in enclosed spaces like laboratories, observatories, museums, cabinets of curiosities, botanical and zoological gardens, libraries, and hospitals - has been one of the principal accomplishments of these recent studies of science" (Raj, 2007, p. 8).
} 
mente rico para quem está interessado nos modos de conceber, organizar, frequentar e preservar o espaço público", a despeito de serem pouco estudados pelas ciências humanas e sociais no Brasil.

No tocante à história dos hortos e jardins botânicos paulistas, foco deste artigo, foram identificados alguns trabalhos que abordam prioritariamente o século XIX e XX, com destaque para o horto botânico depois transformado em jardim público, no bairro da Luz, e o projeto de jardim botânico inaugurado posteriormente, onde hoje fica o Parque Estadual das Fontes do Ipiranga (Rocha, 1999; Rocha \& Cavalheiro, 2001; Dias \& Ohtake, 2011). Do mesmo modo, atenção foi dada ao Horto Oswaldo Cruz instalado no Instituto Butantan, sendo discutida a história da instituição e aspectos do paisagismo da capital paulista (Oliveira et al., 2005; Hingst-Zaher \& Teixeira-Costa, 2016; Molina, 2016), mas nos parece que ainda são necessárias pesquisas que se dediquem às iniciativas ocorridas. Um número cada vez mais expressivo de trabalhos também tem abordado a temática em outras localidades brasileiras, com destaque para o Rio de Janeiro, embora com menor ênfase no período republicado (Heizer, 2007; 2008; Casazza, 2011; Machado \& Alves, 2011; Aleixo \& Lopes Filho, 2014; Florez et al., 2018). Por essa razão, o presente artigo procura contribuir com as investigações que tematizam o conhecimento científico e seus locais de produção, enfocando o Horto Oswaldo Cruz (HOC) criado no Instituto Butantan e dirigido por Frederico Carlos Hoehne, entre 1917 e 1924. Nosso objetivo é analisar a implantação e o desenvolvimento do HOC, destacando as práticas científicas especialmente relacionadas ao cultivo e à criação de uma rede de interlocutores, evidenciando, por um lado, os interesses pessoais de Hoehne, e de outro, as orientações governamentais.

O trabalho, que inicialmente previa o cultivo de espécies vegetais tóxicas e medicinais, ampliou-se com o estabelecimento de uma Seção de Botânica, cujas atividades também abarcaram a administração da Estação Biológica do Alto da Serra, a organização de um herbário e de uma exposição botânica, a realização de viagens científicas, a publicação de textos e a comunicação com interessados no assunto. A trajetória científica e os interesses pessoais de Hoehne foram determinantes no desenvolvimento desses projetos, o que nos leva a destacar aspectos biográficos, dentre os quais, alguns já foram tratados na historiografia. Inicialmente jardineiro-chefe do Museu Nacional e botânico da Expedição Rondon, Hoehne mudou-se para São Paulo com o intuito de assumir o Horto Oswaldo Cruz em 1917. Após período no Instituto Butantan, também trabalhou no Museu Paulista, no Instituto Biológico de Defesa Agrícola e Animal, no Departamento de Botânica e no Instituto de Botânica. Paralelamente, foi reconhecido por sua experiência em expedições científicas e por sua atuação como orquidófilo (Hoehne, 1951; Franco \& Drummond, 2009; Molina \& Norder, 2014; Sá, 2017). A preocupação do botânico com a flora brasileira circunscreveu aspectos técnicos, como descrição, identificação e classificação das plantas, mas foi além e abarcou uma determinada maneira de ver a sociedade. O interesse pelas ciências biológicas e o empenho em difundi-las revelou-se uma questão importante ao longo da carreira - essa área do conhecimento possibilitaria saber mais sobre a fauna e a flora brasileiras, evitaria as depredações e o desaparecimento de espécies. Igualmente, serviria 
à educação do povo para seguir as regras da higiene, levando ao progresso e ao adiantamento moral e intelectual (Hoehne, 1925a, p. 13).

De acordo com Duarte (2010), a ligação entre a biologia e o exercício do poder no Brasil foi crescente desde o início do século $\mathrm{XX}$, tendo vários cientistas atuado em políticas públicas de saúde, o que nos leva, neste artigo, a analisar as políticas científicas e as instruções governamentais para a criação do horto botânico. A atenção à educação também foi compartilhada por outros estudiosos e instituições, como analisado pela referida pesquisadora no estudo sobre o Museu Nacional. Desta maneira, percebe-se que a preocupação de Hoehne com a instrução da população dialogava com os anseios de outros cientistas atuantes no mesmo período, razão pela qual abordaremos algumas das propostas educacionais implementadas junto à criação do HOC.

No que se refere às redes de relações, Franco \& Drummond (2009) analisaram a atuação do botânico vinculada a um grupo de intelectuais que, nas décadas de 1920 a 1940, se viu como responsável pela construção da identidade nacional e pela organização das instituições do Estado. A proteção da natureza era um interesse em comum e o fato de a relacionarem com a questão da identidade nacional possibilitou que se inserissem no contexto político-intelectual do período com relativo sucesso. Dean (2004, p. 272) também chama a atenção para esse aspecto. Hoehne faria parte de uma nova geração de cientistas conservacionistas vinculados ao Estado-nação emergente. Por volta de 1930, "os recursos naturais passavam a ser encarados como uma reserva coletiva a ser utilizada eficientemente em favor da nação" e o botânico, de acordo com o autor, tinha uma concepção de conservação funcionalista, atribuindo ao Estado um papel importante nesse processo.

Tendo como foco as práticas científicas vinculadas aos cultivos e à rede de interlocutores estabelecida por Hoehne, nos apoiaremos na discussão proposta por Jardine \& Spary $(1996$, p. 8) sobre as culturas da História Natural e as práticas desse campo de conhecimento. Os autores indicam que, por ser uma disciplina, a História Natural comporta convenções, habilidades e estratégias denominadas coletivamente de práticas, por meio das quais afirmações são promovidas, garantidas e defendidas. Semelhante ideia pode ser atribuída à botânica e às práticas estabelecidas e compartilhadas por estudiosos e amadores que dão unicidade à área de conhecimento, ao mesmo tempo em que são constituídas por essa mesma área e pelos sujeitos que nela atuam. Acreditamos, portanto, que a temática se aproxima tanto da história das instituições científicas quanto do cotidiano científico, possibilitando novas indagações sobre a história da botânica e sua institucionalização em São Paulo.

Para analisarmos a história do HOC em associação às práticas científicas, utilizamos, principalmente, os relatórios elaborados anualmente pelo próprio Hoehne, com o objetivo de apresentar às autoridades administrativas do Instituto Butantan e do Serviço Sanitário as ações desenvolvidas. Esse material constitui fonte essencial para compreendermos o cotidiano da instituição, destacando aspectos da concepção e funcionamento do HOC.

De forma complementar, utilizamos como fonte documental o "Album da Secção de Botanica do Museu Paulista", escrito por Hoehne e publicado em 1925. Diferentemente dos relatórios, elaborados sequencialmente à realização das atividades e com linguagem formal, o "Album" foi escrito posteriormente à atuação de Hoehne no Instituto Butantan por ocasião 
do oitavo aniversário da Seção de Botânica, momento em que se encontrava vinculada ao Museu Paulista. O livro tinha como propósito despertar o interesse e o amor do público e dos governantes para as ciências biológicas e, em especial, para a botânica (Hoehne, 1925a, p. 13). Serviu, além disso, como um espaço privilegiado em que o autor pôde expor seus pontos de vista, as iniciativas bem-sucedidas, as dificuldades pelas quais passou e os eventuais embates travados com outros estudiosos. Para tornar o texto mais agradável e atrativo, as proposições estéticas e paisagísticas de criação do HOC foram explicitadas juntamente às descrições das atividades, acompanhadas amplamente de fotografias e legendas explicativas.

Outra fonte do presente estudo é o livro de autoria de Hoehne "Resenha histórica para a comemoração do vigesimo anniversario da Secção de Botanica e Agronomia annexa ao Instituto Biologico de São Pau10" (1937). Como informado no título, também é uma publicação comemorativa que marca o aniversário da Seção de Botânica cujo objetivo era recapitular o que foi realizado ao longo de quase 20 anos de trabalho da instituição (Hoehne, 1937, p. 3).

A seguir, faremos uma breve discussão sobre o estabelecimento de hortos e jardins botânicos em São Paulo e, na sequência, enfocaremos o HOC, mostrando o lugar ocupado por ele no Instituto Butantan, assim como as práticas cientificas instituídas.

\section{A criação de hortos e jardins botânicos em São Paulo}

A função dos hortos e jardins botânicos mudou ao longo do tempo, ainda que se reconheça uma continuidade em certas concepções e práticas instituídas. No Brasil, durante o período colonial, o estabelecimento desses locais vinculou-se ao domínio de Portugal e ao papel pragmático e utilitário que as ciências naturais passaram a ter na segunda metade do século XVIII, atreladas ao fortalecimento e à diversificação da economia, bem como à ideia de Estado Moderno, racional e centralizado. Os jardins surgiram em um contexto de otimismo com a possibilidade de maior controle da natureza e com o potencial econômico dos novos produtos naturais (Sanjad, 2001; 2006).

Elaborado por Domingos Vandelli, um vasto projeto de produção da História Natural das colônias portuguesas foi colocado em prática. A aclimatação e o reconhecimento de plantas foi uma das tarefas empreendidas, e o estabelecimento dos jardins botânicos nas colônias contribuiu com essa função (Pataca, 2011). Para Segawa (1996, p. 109-110), as primeiras tentativas da coroa portuguesa de organizar jardins no Brasil envolveram interesses científico, agrícola e econômico: "o objetivo era implementar hortos botânicos em que se pudessem aclimatar plantas úteis ao desenvolvimento do comércio de especiarias na Europa e ampliar o conhecimento sobre novas variedades nativas que pudessem competir com as culturas tradicionais cultivadas no Oriente".

Em São Paulo, a primeira iniciativa no âmbito do estado é atribuída ao Governador da Capitania, Antonio Manoel de Mello Castro e Mendonça em $1799^{2}$, que mandou criar um horto botânico à imitação do que tinha sido estabelecido no Pará, conforme aviso régio. Foram escolhidas terras devolutas no bairro da Luz e, em 1825, o horto foi aberto ao público, tendo permanecido com essa função

\footnotetext{
${ }^{2}$ Há divergências quanto ao ano. Ao analisar a bibliografia que menciona o assunto, Rocha (1999, p. 53) conclui que o aviso régio que ordenou a criação do jardim botânico de São Paulo é de 1799.
} 
até 1838, ano em que a Assembleia Legislativa da província decidiu transformá-lo em jardim público (Marques, [1879] 1952; Segawa, 1996; Rocha, 1999). A história da instituição também chamou a atenção de Hoehne, que se dedicou ao tema no guia elaborado para os visitantes no jardim botânico posteriormente instalado na cidade (Hoehne et al., 1941).

No final do século XIX, outras iniciativas científico-culturais ocorreram envolvendo a criação de novos espaços institucionais e a reformulação dos preexistentes (Figueirôa, 1997). Em São Paulo, Franco \& Drummond (2004) salientam que, a despeito do progresso desejado, alguns setores políticos começaram a considerar os riscos apresentados pela agricultura de plantation e pelo crescimento desordenado da cidade à economia e à manutenção do projeto político. Aproximando-se da ideia de modernização racional, o governo contratou um grupo de técnicos e cientistas tendo em vista o melhor aproveitamento dos recursos naturais. Os autores apontam que as atuações de Orville Derby, F. W. Dafert, Hermann von Ihering, Alberto Loefgren e Edmundo Navarro de Andrade contribuíram com a criação de instituições estaduais que objetivaram a modernização dos estudos científicos. O processo de institucionalização das ciências naturais em São Paulo, além disso, vinculou-se à atuação da Comissão Geográfica e Geológica (CGG), cujos trabalhos estiveram ligados à criação de diversas instituições, dentre as quais o Museu Paulista, o Instituto Florestal e o Instituto Geológico (Figueirôa, 1997).

Alberto Loefgren, botânico da CGG, dirigiu o Horto Botânico da Cantareira onde foram cultivados e estudados vegetais coletados nas expedições pelo oeste do estado de São Paulo. O Museu Paulista, dirigido por Hermann von Ihering, também abrigou um horto botânico em suas dependências. Enquanto no herbário da instituição predominava a sistemática, no horto era possível entrar em contato com "a beleza do reino vegetal em plena liberdade na natureza" (Luederwaldt, 1918, p. 288).

Nesse contexto institucional, em 1917, um local destinado ao estudo da botânica foi igualmente criado no Instituto Butantan. Hoehne foi convidado por Arthur Neiva, diretor do Serviço Sanitário de São Paulo, para iniciar um horto com o objetivo de que fossem cultivadas plantas tóxicas e medicinais. Esse foi o início da aproximação de Hoehne com o governo paulista, relação que se mostraria bastante profícua nos anos subsequentes. O botânico participou de inúmeras expedições científicas, publicou intensamente e tornou-se reconhecido pelos trabalhos desenvolvidos na Seção de Botânica, posteriormente transformada em Departamento de Botânica.

No Instituto Butantan, o projeto de se estabelecer um horto teve suas especificidades, sendo marcado por questões econômicas, políticas e sociais do período, notadamente por preocupações concernentes ao Serviço Sanitário, entidade ao qual estava atrelado. A tomada de decisões e ações empreendidas circunscreveu tanto as pessoas que atuaram na delimitação das políticas públicas, quanto aqueles que se aproximaram dos fazeres cotidianos. Nessa perspectiva, Hoehne é uma figura central, pois se relacionava com as instâncias governamentais, ao mesmo tempo em que atendia às questões prementes do dia a dia, tendo que lidar com a definição das espécies vegetais que seriam cultivadas, a gestão dos trabalhadores, as limitações impostas pelos recursos disponíveis, a divulgação das atividades desenvolvidas e a comunicação empreendida com interessados no assunto. 


\section{O Instituto Butantan e o Horto Oswaldo Cruz}

O Instituto Butantan foi criado em 1901, em decorrência da preocupação com a peste bubônica no final do século XIX e a urgência de se ter um soro curativo. Emílio Ribas, diretor do Serviço Sanitário, defendia que uma política sanitária efetiva deveria se apoiar na aliança entre a microbiologia e a higiene (Almeida, 2005, p. 85). Esse momento foi marcado pela criação de outras instituições de pesquisa e prestação de serviços nas áreas médica e biológica no eixo Rio-São Paulo, o que demonstrava o valor atribuído aos novos conhecimentos embasados nos estudos de Pasteur (Gualtieri, 1994, p. 5).

De acordo com Dantes, os institutos de pesquisa tiveram um papel importante na produção científica brasileira, veiculando a moderna concepção de pesquisa experimental e formando as primeiras gerações de pesquisadores brasileiros. Tanto os governos estaduais quanto o federal iniciaram um programa de reorganização do serviço sanitário com o objetivo de combater as epidemias existentes naquele momento: "Era um programa prioritário, já que as epidemias, difundindo uma imagem negativa do País no exterior, eram um empecilho à política de imigração de mão-de-obra estrangeira" (Dantes, 1979-1980, p. 350).

Os primeiros anos de funcionamento do Instituto Butantan, entre 1901 e 1919, foram marcados por uma estabilidade institucional, tendo Vital Brazil atuado como diretor nesse período. O momento coincidiu com a também estabilidade da direção do Serviço Sanitário que tinha à frente de suas atividades Emílio Ribas, cuja atuação ocorreu de 1898 a 1917 (Gualtieri, 1994, p. 28-29). Já na ocasião de criação do HOC, o Serviço Sanitário não só tinha um novo diretor, como também passou por uma reestruturação que estabeleceu novas atribuições ao Instituto Butantan. A lei promulgada em 1917 definiu que a instituição era destinada "ao preparo dos sôros, vaccinas, produtos opotherapicos e outros que a sciencia e pratica tenham sancionado", determinou o "estudo e cultivo de plantas venenosas e medicinaes" e também o "estudo das epizootias que aparecerem no Estado e seu tratamento" (São Paulo, 29 dez. 1917).

As ações desenvolvidas no Instituto Butantan relacionaram-se às discussões sobre a saúde da população, à necessidade de reforma dos serviços prestados e à extensão das ações governamentais às zonas rurais. Discutir saúde, para Benchimol \& Teixeira (1993, p. 93), implicava questionar o modelo de civilização do país: "Saúde era o prisma que refratava os parâmetros sociais, culturais, políticos e geográficos da modernização desejada por todos os grupos sociais descontentes". Os autores ponderam, entretanto, que a atuação de Neiva também foi marcada pela disputa travada com Carlos Chagas. Se, por um lado, os objetivos de Neiva centravam-se nas demandas da saúde pública, por outro, parte de suas preocupações extrapolava tal esfera: "o Butantan devia se transformar numa instituição capaz de competir com o Instituto Oswaldo Cruz na comercialização destes quimioterápicos, de soros, de vacinas e de uma nova categoria de terapêuticos, os opoterápicos" (Benchimol \& Teixeira, 1993, p. 114). A disputa estabelecida entre Neiva e Chagas não só envolveu as entidades paulista e carioca, como abarcou a própria chefia nacional da saúde pública e o posto de destaque que ambos tinham pretensão em ocupar. $\mathrm{O}$ estudo da botânica, nesse contexto, é uma faceta de um projeto mais amplo 
e explicita os diversos interesses que estavam em jogo no período.

O HOC, inaugurado oficialmente em 1918, permaneceu até 1924 sob responsabilidade de Hoehne. Os objetivos previam "enriquecer o patrimonio therapeutico, fornecer informações e recursos à medicina, orientar o público na arte de curar as molestias e agir contra o charlatanismo e a exploração dos hervanarios e curandeiros destituidos de escrúpulos (...)" (Hoehne, 1925a, p. 39). A mudança da direção foi decorrência da desanexação da Seção de Botânica do Instituto Butantan e sua incorporação ao Museu Paulista (São Paulo, 29 dez. 1922). Tal transferência gerou intensos debates no âmbito legislativo e também desavenças entre Hoehne e seus superiores, evidenciando a intrínseca relação entre as instâncias científicas e políticas. Com a decisão de que a Seção de Botânica do Instituto Butantan passaria a ser incorporada integralmente ao Museu Paulista, o Horto Oswaldo Cruz permaneceu no local de origem sob os cuidados de Hoehne que, ao invés de responder ao diretor da instituição, passou a prestar contas a Affonso Taunay, responsável pelo Museu Paulista. A interrupção do trabalho do botânico ocorreu somente em janeiro de 1925, quando o governo solicitou que a área voltasse a ser de responsabilidade do Instituto Butantan (Hoehne, 1925b, p. 6).

A história da Seção de Botânica tem também suas particularidades, embora não seja o foco deste artigo. Vinculada inicialmente ao Instituto Butantan, foi anexada ao Museu Paulista e, em 1928, transferida novamente para o Instituto Biológico de Defesa Agrícola e Animal. Em 1938, a Seção foi desvinculada do Instituto Biológico e transformada em Departamento de Botânica. Alguns anos depois, em 1942, uma nova organização estabeleceu o Ins- tituto de Botânica. Durante esse período, Hoehne seguiu sendo o responsável pelos trabalhos, até aposentar-se em 1952 (Teixeira, 1988).

\section{Entre orientações governamentais e práticas científicas: o dia a dia do horto}

A lei de 1917 foi sucinta ao definir que caberia ao Instituto Butantan o estudo e cultivo de plantas venenosas e medicinais. As demais orientações couberam ao Serviço Sanitário e à direção do próprio Instituto. Um olhar para o do dia a dia do local dá notícias de como as orientações governamentais desdobraram-se em ações a partir do trabalho dirigido por Hoehne.

O HOC foi instalado em uma várzea irregular, em parte inclinada, que abrigava um capinzal verde e também um mandiocal. Os trabalhos tiveram início com o preparo dessa área e incluiu o traçado de um plano geral para a instalação. O projeto (Figura 1) tinha predominantemente linhas retas, conforme "os processos e methodos mais modernos da esthetica" e foi inspirado no Jardim Botânico de Dahlem, em Berlim, com o diferencial de que os objetivos eram muitos mais modestos do que os da referência estrangeira (Hoehne, 1925a, p. 41). Hingst-Zaher \& Teixeira-Costa (2016, p. 107-108) destacam o valor do aspecto estético e a influência europeia no paisagismo: "Embora o Horto ainda não fosse aberto à visitação, uma análise das fotos da época revela o HOC como um espaço aberto, sem muros, que poderia ser contemplada pelos visitantes sem a necessidade de entrada no espaço de cultivo das plantas".

A cada ano, mudanças ocorreram na estrutura do local: algumas ruas foram construídas, um lago 


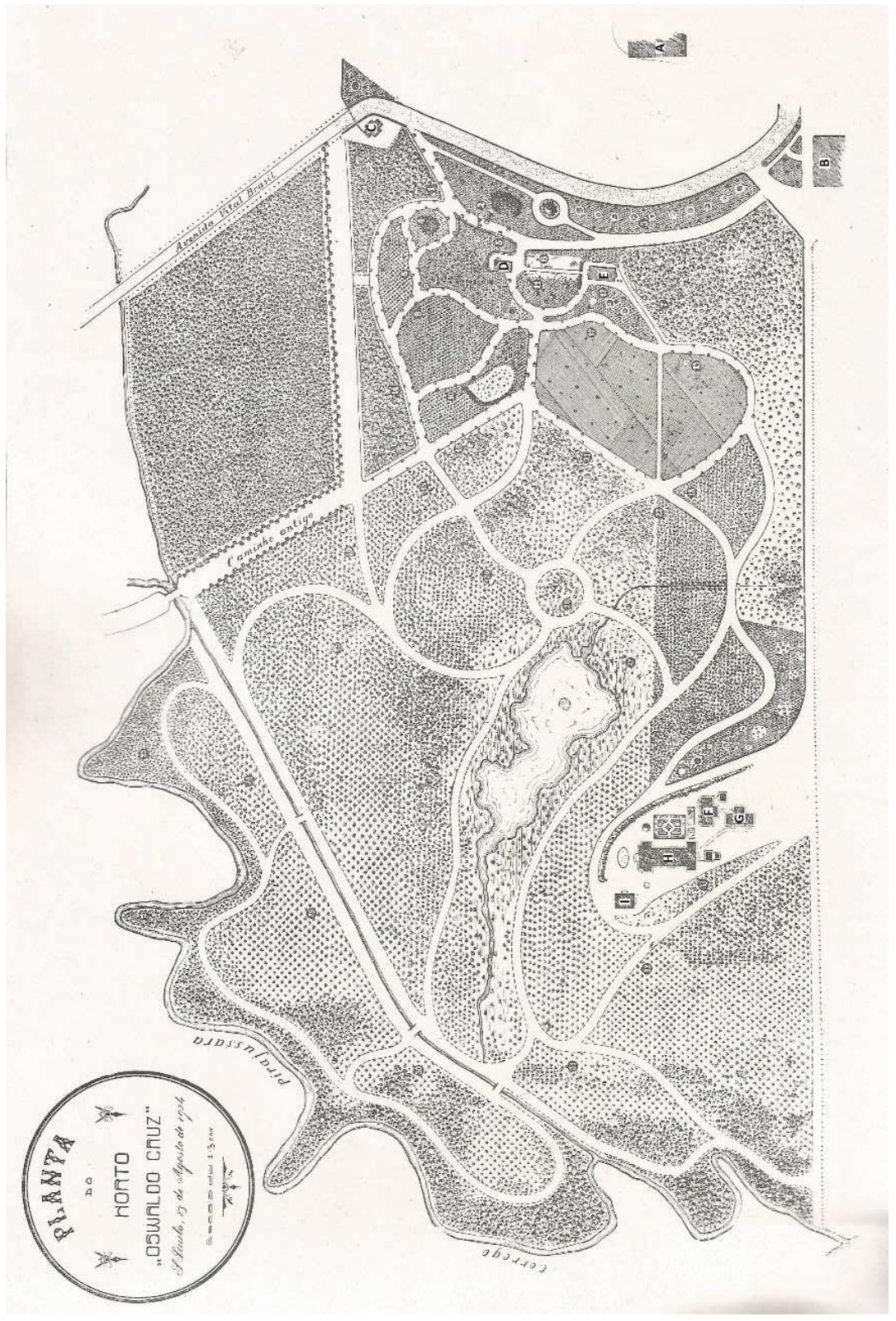

FIGURA 1 - Planta do Horto Oswaldo Cruz localizado no Instituto Butantan (SP), de acordo com o projeto esboçado e aceito em 1917. Levantamento e desenho de Joaquim Toledo. É possível observar: A) Ponto em que fica o Instituto; B) Cocheira; C) Portão e centro telefônico do estabelecimento; D) Estufa do horto; E) Alpendre para secagem e depósito de sementes; F-I) Ex-Instituto de Medicamentos Oficiais do Estado; F) Pavilhão da sede da Seção de Botânica; G) Depósito de vidros e residência do Sr. Guilherme Gehrt; H) Ex-laboratório químico; I) Casa do porteiro. FONTE: Hoehne (1925a, p. 42). 
foi projetado e um alpendre foi erguido destinado à secagem, armazenamento e acondicionamento das sementes. Também foi instalada uma estufa para a cultura de espécies vegetais tropicais e outras que exigiam muita umidade atmosférica (Figura 2). $\mathrm{O}$ interesse de Hoehne pelas orquídeas parece ter sido um dos fatores que contribuiu para o cultivo. A estufa abrigou mais de 120 espécies, muitas delas colhidas pelo próprio estudioso em excursões científicas pelos estados de Minas Gerais e São Paulo. $\mathrm{O}$ propósito inicial, entretanto, era o de cultivar as espécies medicinais e tóxicas das regiões mais cálidas durante o inverno, com o intuito de "estudar essas mesmas plantas quanto á relação existente entre os alcaloides e outros princípios activos e o maior ou menor grau de calor do ambiente em que se desenvolvem" (Hoehne, 1925a, p. 50). Atribuindo a não exequibilidade do projeto aos poderes públicos, o botânico optou por aproveitar a estufa para a cultura de orquídeas e outras plantas de regiões mais quentes.

A inauguração do HOC foi noticiada pela imprensa paulista, que destacou o propósito da iniciativa e os discursos das autoridades feitos na ocasião. Dentre os presentes estiveram o presidente do Estado, os secretários do Interior, da Fazenda, da Agricultura, da Justiça e médicos que compunham os departamentos do Serviço Sanitário. Arthur Neiva ressaltou o importante papel da indústria e do saneamento no país e defendeu que o Instituto se dedicasse à produção de quinina, substância usada no tratamento da malária (Anon., 1918, p. 3).

A proposta contou com apoio governamental e ocasionou na criação do Instituto de Quinina, que não chegou a funcionar devido à falta de matéria prima. Estabeleceu-se, posteriormente, o Instituto de Medicamentos Oficiais do Estado, cujo objetivo era desenvolver medicamentos usados no trata-

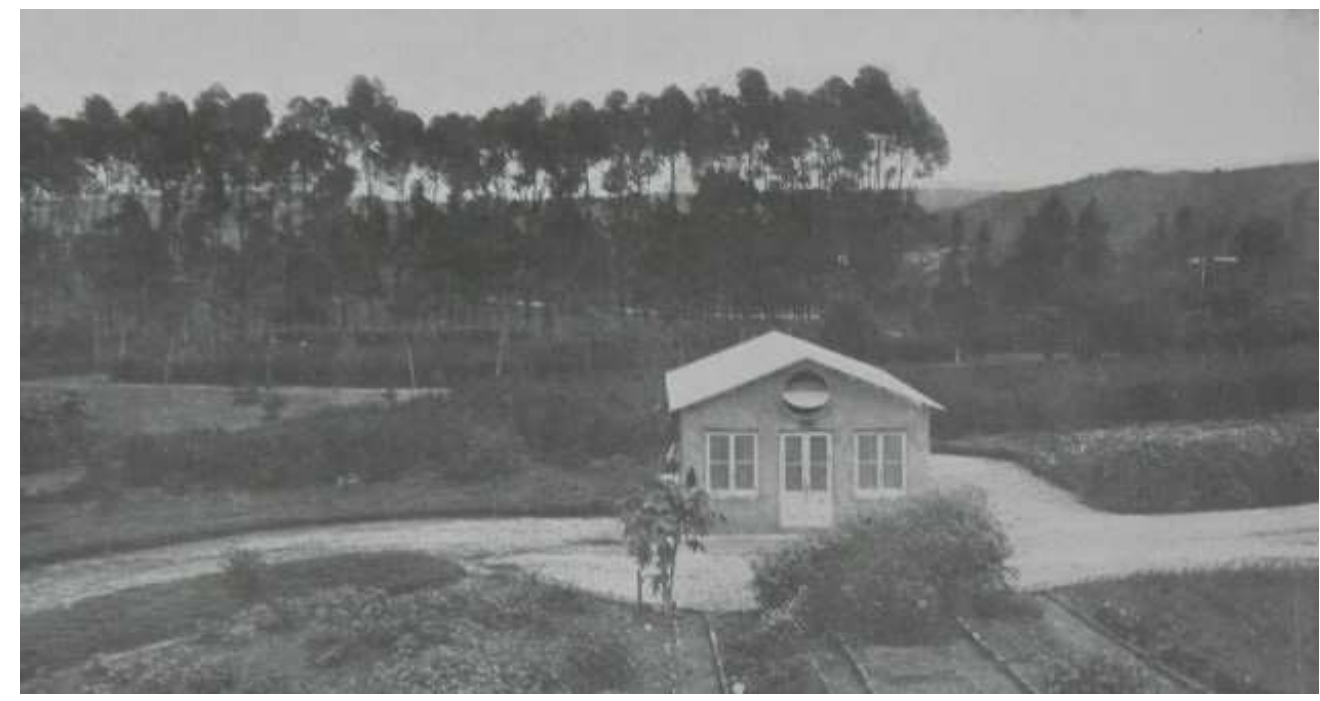

FIGURA 2 - A estufa do Horto Oswaldo Cruz, em 1918, onde eram cultivadas espécies vegetais tropicais. Instituto Butantan, São Paulo. FONTE: Hoehne (1925a, p. 41). 
mento e profilaxia de diversas doenças; estudar os princípios tóxicos-medicamentosos dos vegetais cultivados no Horto Oswaldo Cruz e extrair e preparar os princípios ativos de vegetais brasileiros amplamente usados na medicina (São Paulo, 26 dez. 1919). Tais iniciativas ecoavam uma preocupação com a produção de medicamentos e com a saúde pública da população. O estudo da botânica colocava-se como um aspecto de um projeto mais amplo planejado para o Instituto Butantan que respondia diretamente aos anseios e objetivos do Serviço Sanitário do Estado.

Juntamente com o horto previu-se a criação de um laboratório de química - para o preparo e análise química e farmacológica dos produtos vegetais -, e um gabinete de fisiologia experimental - para a realização de experiências com as substâncias e drogas fornecidas pelo laboratório com a finalidade de que fossem usados na terapêutica, indústria e veterinária (Hoehne, 1925a, p. 39). O estudo da botânica e sua crescente especialização envolveu cultivos, mas também a análise química e fisiológica das espécies. Outros profissionais foram requisitados e houve a necessidade de novas instalações e aparato material, razão pela qual seriam requisitados recorrentemente por Hoehne e Vital Brazil.

As atividades do primeiro ano do horto abarcaram a organização de um herbário, o plantio de exemplares de vegetais arborescentes e a cultura de plantas medicinais exóticas. A análise dos relatórios institucionais explicita como os objetivos traçados foram traduzidos em ações cotidianas, colocando em destaque as práticas de cultivo e as experimentações ocorridas no horto, assim como as escolhas feitas e os interesses envolvidos. O olhar para essas atividades corriqueiras se aproxima do que Cunningham (1996, p. 53-54) destacou sobre a história da jardinagem - por meio dela, seria possível saber mais sobre o cultivo prático de jardins, a história da horticultura, da "baixa cultura", de como os jardins foram realmente cultivados e por quem. Reconhecendo as devidas particularidades do cultivo nos jardins e nos hortos botânicos, acreditamos que tais questões podem ser evidenciadas ao enfocarmos o dia a dia no HOC.

Além do preparo do terreno e da organização de um plano geral, foi enviada uma circular aos agricultores com o pedido de que mandassem mudas e sementes de plantas tóxicas ou medicinais, juntamente com a indicação do nome popular, o local e a data em que foram colhidas (Brazil, 1917, p. 18; Anon., 1917, p. 3). A iniciativa surtiu efeito e vários correspondentes colocaram-se à disposição, enviaram exemplares vegetais e fizeram perguntas sobre os procedimentos relativos às remessas. Hoehne, ao verificar o estado deteriorado com que muitos materiais chegaram, escreveu orientações sobre o assunto abordando a colheita, o preparo e a remessa de plantas vivas, sementes e amostras de vegetais para identificação (Hoehne, s/d). O texto foi encaminhado por correio aos interessados, evidenciando a complexa tarefa de se formar uma coleção botânica, atividade que envolvia a aquisição de espécimes, a formação de uma rede de contatos e também o ensino dos procedimentos adequados. A comunicação com terceiros era um aspecto importante e uma prática já existente no Instituto Butantan. Ibañes et al. (2006, p. 79) apontam que desde o início a vulgarização e a divulgação científica faziam parte da missão do Instituto - a "estratégia de aliança com os proprietários rurais e troca de cobras por soros (escambo) reforçam essa vocação, ampliando a difusão científica do Instituto”. Já na década de 1920, de acordo com Bezerra (2009, p. 112), observou-se 
uma crescente diversificação nas estratégias de ensino e divulgação realizadas no Instituto Butantan, embora as ações sejam consideradas tímidas devido ao caráter pontual com que ocorreram.

Ao fazer um balanço das atividades iniciais, Hoehne ponderou sobre a natureza do serviço envolvido, que demandaria esforço, persistência e tempo para a realização de algo que pudesse ser apresentado e que fosse realmente útil. Justificou, por isso, o pouco realizado considerando o que era desejado. Distinguiu o trabalho feito nos hortos botânicos e herbários dos que ocorreriam em parques ou jardins comuns, procurando demonstrar a árdua tarefa à qual se dedicou - se, do ponto de vista de um leigo, esses espaços diferiam pouco entre si, apontou que os primeiros distinguiam-se dos demais pelo tempo indispensável para a aquisição, desenvolvimento e determinação das espécies a cultivar, atividades essas que não aconteceriam da noite para o dia (Hoehne, 1917).

Os trabalhos realizados seguiram as orientações dos diretores do Instituto Butantan e do Serviço Sanitário, e priorizaram o cultivo de espécies de Mentha e Chenopodium, devido ao fato de a essência ser utilizada no combate aos vermes intestinais. Outras inúmeras espécies foram cultivadas. Do grupo de medicinais exóticas foram contempladas Linum usitatissimum (linhaça ou linho), Coriandrum sativum (coentro), Mentha pulegium (poejo), Helianthus annuus (girassol), Malva sylvestris (malva), Brassica nigra (mostarda) e Atropa belladonna (beladona). Também foram plantados exemplares de plantas medicinais exóticas arborescentes, espécies indígenas consideradas tóxicas e medicinais, essências florestais no geral, espécies dos campos e capões, além de outras que forneciam madeira para construções.

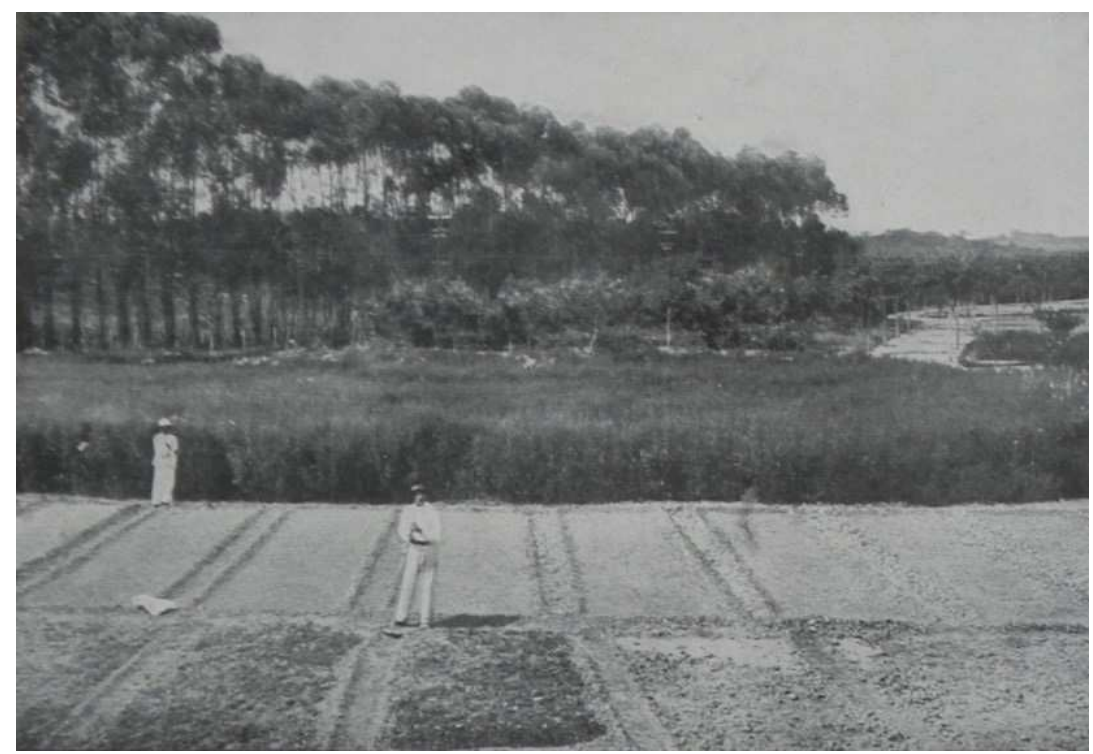

FIGURA 3 - Canteiro para sementeiras de leguminosas forrageiras, além de Chenopodium ambrosioides, no Horto Oswaldo Cruz (Instituto Butantan, São Paulo).

FONTE: Hoehne (1925a, p. 63). 
Algumas espécies cultivadas destacadas por Hoehne tinham como intuito o estudo da emetina, utilizada em preparos com fins medicinais. A escolha também abarcou exemplares considerados altamente tóxicos para o gado vacum, como Rhynchosia phaseoloides (olho de cabra ou de pombo). O cultivo de Chenopodium ambrosioides (erva-de-santa-maria) foi progressivamente ampliado, dado que o óleo essencial era reconhecido como o melhor anti-helmíntico (Figura 3). Algumas experiências ocorreram para averiguar a melhor época do ano para o plantio e para a produção do óleo. De acordo com Hoehne, a ausência de um químico o levou a iniciar os trabalhos de destilação da erva, procedimento iniciado com o aproveitamento das folhas e sumidades floridas e frutificadas. Posteriormente, outras variações foram experimentadas e confirmou-se, por fim, que a essência obtida das sementes secadas à sombra era a mais ativa. $\mathrm{O}$ trabalho previa que as sementes fossem recolhidas diariamente e, considerando-se que era uma atividade que requeria mais cuidado, agilidade e pouca energia, foram admitidos alguns meninos que recebiam a metade do salário dos adultos. A produção passou a ser de responsabilidade do Instituto de Medicamentos Oficiais, colaboração que durou um curto período devido à interrupção das atividades desse Instituto, em 1921 (Hoehne, 1920; Hoehne, 1925a, p. 43-46).

Outros estudos e ensaios ocorreram com plantas forrageiras e têxteis consideradas raras e menos conhecidas. A cultura de algumas espécies, por outro lado, não foi ampliada ou foi até reduzida por não se ter informações sobre a conveniência do aproveitamento dos princípios terapêuticos pelo
Instituto. Em 1923, foi destacado o prosseguimento dos serviços, o cultivo de um novo amendoim que vinha despertando o interesse de agricultores e o estudo de árvores com o fim de que fossem usadas na arborização de ruas e como objeto de adorno (Secretaria do Interior, 1923). No ano seguinte, embora os melhoramentos não tenham sido de grande importância, Hoehne frisou que a conservação aconteceu com o máximo cuidado e atenção (Hoehne, 1924, p. 3).

Ao longo dos anos, uma grande variedade de espécies vegetais foi mencionada nos relatórios institucionais e é possível perceber que a cultura de algumas delas atendeu a interesses não relacionados às propriedades tóxicas e medicinais. $\mathrm{O}$ estudo da adaptação e da cultura das leguminosas forrageiras, de acordo com o botânico, foi um pedido feito por diversos criadores do estado de São Paulo e do editor da revista Chacaras e Quintaes, cuja preocupação envolvia a pecuária ${ }^{3}$. O cultivo era defendido pelo diretor da Seção como uma questão de patriotismo: “(...) julgamos que de nada adeantam a introducção de bons reproductores e as conferencias e commentarios sobre a pecuaria nacional, sem que se não tenha dado primeiro solucção a questão primordial que é da alimentação do gado. Embóra esta questão nada tenha que ver com os objectivos do Horto 'Oswaldo Cruz', deveriamos, ao menos por patriotismo, cuidar della” (Hoehne, 1919, p. 227).

A valorização da flora brasileira e o amor à pátria foram dois aspectos presentes na atuação do botânico. A administração do horto e da Seção de Botânica resvalou nessas questões, explicitadas em seus escritos:

${ }^{3}$ A Revista Chacaras e Quintaes foi editada pelo Conde Barbiellini e publicada mensalmente entre os anos de 1909 e 1969. Durante as décadas de 1910 e 1920, dedicou-se quase exclusivamente à vulgarização técnico-científica (Antuniassi \& Moura, 2005). 
Temos nos esforçado não só para manter, mas tambem para ampliar cada vez mais as relações scientificas com varios especialistas de nomeada e estabelecimentos de primeira ordem, porque partimos do principio de que este é um meio pratico de darmos signal de vida da Secção, como ainda de fazermos propaganda do progresso do Estado e, por conseguinte, do Brasil (Hoehne, 1920, p. 74).

As trocas que ocorreram com outros estabelecimentos dedicados ao estudo da botânica foram bastante valorizadas - além de ser uma prática corrente entre os estudiosos e instituições, era uma forma de divulgar o trabalho que estava acontecendo. Ressaltava, entretanto, fazê-lo em benefício da pátria:

Entrando em correspondencia a permuta com os estabelecimentos botanicos e acceitando a collaboração de especialistas empenhamos não só o nosso nome, mas também o do Estado, a quem cabe proporcionar os meios para conserval-o na altura de merecer continuamente e cada vez mais completa a confiança de todos. E nisto tudo não deveis procurar vaidade pessoal, nem interesse particular: trabalhando para o desenvolvimento da Secção de Botanica do Instituto, a nós confiada, visamos o engrandecimento da Patria, deante de que se esvae a nossa personalidade como pequeno e passageiro collaborador (Hoehne, 1920, p. 74).

As decisões tomadas no dia a dia estavam respaldadas pelas orientações governamentais, mas foram também motivadas por suas crenças e convicções. A análise do que foi plantado no horto igualmente revela aspectos interessantes sobre as escolhas feitas e os trabalhos desenvolvidos no local. Hingst-Zaher \& Teixeira-Costa (2016), no estudo que fizeram a partir do Catálogo do Herbário e das espécies cultivadas no Horto Oswaldo Cruz, indicaram que, de um total de 164 espécies plantadas, $80 \%$ eram nativas, o que vai ao encontro da concepção do próprio Hoehne de valorizar a flora brasileira. Em relação aos hábitos da vegetação selecionada, identificaram que 53 eram arbóreas (32\%), 15 arbustivas (10\%), 37 epifíticas (22\%), 50 herbáceas $(30 \%)$ e 9 lianescentes $(6 \%)$. O estudo das espécies originalmente plantadas também evidenciou que $37 \%$ das plantas (60 espécies) não se enquadravam na classificação de interesse tóxico ou medicinal, sendo a maioria reconhecida pelo grande potencial paisagístico e usada ainda hoje com esse fim, tais como Bactris setosa (palmeira-tucum, Arecaceae) e Bougainvillea spectabilis (primavera, Nyctaginaceae). Além de espécies importantes no paisagismo, as autoras identificaram algumas utilizadas na alimentação e outras utilizadas na produção e tingimento de tecidos. Concluíram que o horto, na prática, constituiu-se como uma área de cultivo das chamadas plantas úteis: "Embora careça de uma definição formal na literatura, o termo pode ser entendido como fazendo referência a plantas de interesse comercial, o que inclui, sem restringir, todos os usos mencionados - medicinal, farmacêutico, tóxico, alimentício, de vestuário e paisagístico" (Hingst-Zaher \& Teixeira-Costa, 2016, p. 113).

Essa variedade de espécies foi mencionada por Hoehne nos relatórios anuais da instituição. A nosso ver, o cultivo não era desinteressado e o botânico levava em consideração tanto a utilidade das plantas quanto os seus próprios interesses e os pedidos de seus interlocutores, evidenciando uma preocupação não somente com a saúde, mas também com a pecuária, a agricultura, o paisagismo e a indústria. 


\section{Plantas, pessoas e condições materiais}

Ainda que centrais, as atividades de cultivo não foram as únicas desenvolvidas no HOC. Os trabalhos publicados e as excursões científicas compreenderam outras facetas do que foi realizado. Enquanto as publicações indicavam a vitalidade dos institutos de ciência, as excursões científicas, as pesquisas in loco e a colheita de plantas eram essenciais para a elaboração do herbário, de hortos e jardins (Hoehne, 1937, p. 45). Além de informações sobre o horto serem noticiadas na imprensa paulista, Hoehne teve muitos textos de sua autoria publicados, o que contribuiu com a divulgação do conhecimento biológico, algo tão caro a ele.

A despeito dos progressos ressaltados, diversos foram os problemas relatados nos relatórios institucionais, a maioria decorrente do orçamento limitado destinado à Seção de Botânica. A deficiência de mão de obra foi mencionada ao longo dos anos e apontada como prejudicial. Num episódio narrado, os trabalhadores do horto foram designados para cumprir distintos serviços no Instituto Butantan; em outro, foram acometidos por uma moléstia. Fato é que ano após ano o número reduzido de pessoal e a baixa remuneração tornaram-se um obstáculo para o desenvolvimento das atividades. Procurando a melhoria dos serviços prestados, o botânico reivindicou o aumento de verba para a instalação e para a contratação de trabalhadores: deveria haver pelo menos 30 homens, dado que este número, argumentava, é "a metade daquelle que conta o Jardim Botanico do Rio de Janeiro, que entretanto, é uma instituição feita e que só exige conservação e que não visa producção nem pretende resolver questões como estas que preocupam o nosso Horto" (Hoehne, 1919, p. 228). Também foi solicitada uma mudança na gestão, de modo que tivesse mais autonomia e controlasse a verba e o pessoal: "A verba, para que melhor e mais praticamente possa distribuir e empregal-a de acordo com as necessidades e a urgencia dos serviços e, o pessoal, para que sobre elle possa exercer maior força moral" (Hoehne, 1919, p. 229).

Apesar dos pedidos, não temos informações de que tenham sido acatados. O número de funcionários, pelo contrário, foi reduzido em 1920, pois o botânico priorizou o aumento da diária dos trabalhadores. O pessoal disponível só tinha condições de cuidar da conservação das atividades realizadas e o baixo valor do pagamento era um problema adicional: "Este facto nos colloca em pessima situação quanto á escolha de trabalhadores, porque só os que são recusados pelos particulares nos procuram e, ainda assim, temporariamente, isto é, emquanto não conseguem cousa melhor" (Hoehne, 1920, p. 78). Além de se contentarem com o "refugo", as especificidades dos serviços ficavam em segundo plano. Seria necessário, por exemplo, que algumas atividades fossem feitas por uma única pessoa e acompanhadas durante anos, algo não realizado devido às trocas constantes. A baixa remuneração era um problema que atingia não só a Seção de Botânica, mas todo o Instituto, e foi assunto abordado pelos diretores do Instituto Butantan.

Como recorda Dantes (1979-1980, p. 376), a situação de desamparo do pesquisador científico no Brasil não era exatamente nova e já "no século XIX os salários dos técnicos do Museu Nacional eram inferiores aos dos professores das escolas profissionais de nível superior, o que revela a inexistência de um reconhecimento social da função desempenhada pelo pesquisador". Em relação ao orçamento disponível, a análise da verba destinada ao Instituto Butantan indica que em 1919 houve um 
aumento significativo (Benchimol \& Teixeira, 1993, p. 118; Gualtieri, 1994, p. 94-98). A diferença no valor correspondeu à ampliação das atribuições da instituição após a reforma do Serviço Sanitário de 1917. Entretanto, as frequentes queixas de Hoehne deixam transparecer que o valor destinado à Seção de Botânica era insuficiente tendo em vista os objetivos estabelecidos.

Outros obstáculos para o desenvolvimento do horto diziam respeito às condições materiais e incluíam a aquisição de instrumentos agrários e máquinas destinadas ao preparo das sementes e óleos. A falta de bibliografia especializada era considerada ainda mais grave, pois necessária para a determinação das espécies adicionadas ao herbário e para aquelas enviadas pelos correspondes para identificação. De acordo com Hoehne, as consultas representavam a parte mais útil de qualquer estabelecimento científico e a obra Flora brasiliensis, de Martius, era central para a tarefa ${ }^{4}$.

As condições de trabalho influenciaram as decisões tomadas e a realização dos cultivos, muitas vezes impondo limites ao que se pretendia fazer. Para o botânico, a ausência dos dois laboratórios previstos tornou a ação do horto improfícua, tendo ele voltado a atenção ao herbário e a outras espécies.

No horto fôram, desde então, cultivadas, ao lado das medicamentosas e toxicas, as plantas que são interessantes sob outros pontos de vista. Mereceram nossa attenção as Leguminosas forrageiras, cuja analyse obtivemos do Instituto Agronomico de Campinas e do Instituto de Chimica do Rio de Janeiro; dedicamos algum tempo ás plantas decorativas, fazendo estudos sobre as Orchidaceas em collaboração com o Dr. Ru- dolph Schlechter, em Berlim; tratamos do problema da arborisação das ruas e praças publicas, seleccionamos e observamos diversas arvores da flora indigena que são mais indicadas para esse fim; fizemos experiencias com trigo, fumo e amendoim (Hoehne, 1925a, p. 45).

Se, por um lado, o planejamento foi alterado tendo em vista as condições materiais e econômicas dadas, por outro, um aspecto enaltecido por Hoehne foram as trocas estabelecidas com interessados no assunto, fossem eles especialistas ou amadores. As consultas realizadas pela Seção de Botânica indicam os contatos e trocas ocorridas ao longo dos anos. Se em 1917 e 1918 o número se aproximou de 100 atendimentos anuais, nos anos subsequentes ficou acima de 200, aumento provavelmente relacionado à maior visibilidade da Seção. Referindo-se aos contatos estabelecidos de 1917 a 1937, o botânico indicou que versaram sobre bibliografia, agricultura, defesa vegetal, distribuição geográfica ou origem das espécies, sendo a maioria referente à ordem taxonômica (Hoehne, 1937, p. 52).

TABELA 1 - Consultas atendidas pela Seção de Botânica do Instituto Butantan (1917-1924).

\begin{tabular}{cc}
\hline Ano & Número de consultas \\
\hline 1917 & 109 \\
1918 & 134 \\
1919 & 263 \\
1920 & 280 \\
1921 & 257 \\
1922 & 204 \\
1923 & 260 \\
1924 & 416 \\
\hline
\end{tabular}

FONTE: Hoehne (1937, p. 51).

\footnotetext{
${ }^{4}$ A obra escrita entre 1840 e 1906 é uma referência na botânica. O projeto "Flora brasiliensis" desenvolvido pelo Centro de Referência em Informação Ambiental, pela Universidade Estadual de Campinas e pelo Jardim Botânico de Missouri disponibiliza as imagens das pranchas de famílias selecionadas descritas na publicação. Consultar: http://florabrasiliensis.cria.org.br/.
} 
Parte dessas consultas foi resultado da solicitação, feita por Vital Brazil, de que fossem enviadas mudas e sementes na ocasião em que o horto foi criado. A correspondência existente evidencia a participação de anônimos que ajudaram a compor a coleção da Seção de Botânica com o material enviado e, ao mesmo tempo, contribuíram com a constituição de uma rede de relações que foi se expandindo e fortalecendo à medida que o horto $\mathrm{e}$ a Seção passaram a ser mais conhecidos. A troca de informações ocorreu nas duas direções - ora os interlocutores informavam aquilo que sabiam sobre os espécimes vegetais enviados e o uso popular que tinham, ora Vital Brazil e Hoehne respondiam aos comentários acrescendo novas informações técnicas ou respondendo às perguntas feitas (Instituto Butantan, 1917).

Ainda que Hoehne tenha deixado de dirigir o HOC, continuou a ampliar a comunicação e as trocas realizadas com terceiros, em anos posteriores, ao atuar como responsável pela Seção de Botânica do Museu Paulista.

\section{Considerações finais}

A construção do HOC no Instituto Butantan gerou mudanças institucionais: novos espaços foram criados e projetos desenvolvidos. Acompanhar o dia a dia por meio dos relatórios e das publicações de Hoehne evidencia as várias facetas que compreenderam o trabalho de botânica no local: a cultura de diferentes espécies; as experiências ocorridas relacionadas à melhor época de plantação; a identificação e classificação; a comunicação estabelecida com terceiros; as ofertas recebidas e enviadas; a relação com os trabalhadores, entre outros.
O relato de Hoehne joga luz à história do Instituto Butantan, ao trabalho empreendido no local, às iniciativas bem-sucedidas e malsucedidas, mas vai além ao explicitar fazeres característicos da área e compartilhados por interessados no assunto. Os trabalhos desenvolvidos seguiram orientações governamentais e tinham o propósito de cultivar e estudar as plantas tóxicas e medicinais. Não obstante, foi possível perceber que outros objetivos passaram a ser contemplados ao longo dos anos. Os interlocutores da Seção de Botânica, as preferências de Hoehne e os limites impostos pelas condições materiais foram aspectos que influenciaram no cotidiano e ajudaram a delimitar o que foi realizado.

Com a transferência da Seção de Botânica para o Museu Paulista, ocorreu uma significativa mudança no trabalho desenvolvido, mas não uma total ruptura. No Instituto Butantan, a experiência foi marcada espacialmente e, em anos posteriores, a botânica voltou a ser tema de interesse (Oliveira et al., 2005). Já no Museu Paulista, a Seção foi integrar-se à coleção botânica existente no local, ganhando mais autonomia em 1925, com o novo regulamento da instituição.

\section{Referências}

Anônimo. Notas. Correio Paulistano, São Paulo, 18 jun. 1917. p. 3.

Anônimo. Um estabelecimento modelo. Correio Paulistano, São Paulo, 21 fev. 1918. p. 3.

Aleixo, J. L. M.; Lopes Filho, J. D. Horto medicinal Frei Velloso: 25 anos de criação. Gerais: Revista de Saúde Pública do SUS/MG, 2(1), 21-32, 2014. Disponível em: http://revistageraissaude.mg.gov.br/index.php/gerais41/ article/view/289. 
Almeida, M. de. São Paulo na virada do século XX: um laboratório de saúde pública para o Brasil. Tempo, 19, 7789, 2005. Disponível em: http://www.scielo.br/pdf/tem/ v10n19/v10n19a06.pdf.

Antuniassi, M. H. R.; Moura, M. I. G. L. de. A Revista Chácaras e Quintaes e a comunicação rural. Cadernos CERU, 16, 183-192, 2005. Disponível em: http://www.revistas.usp. br/ceru/article/view/75351.

Benchimol, J. L.; Teixeira, L. A. Cobras, lagartos \& outros bichos: uma história comparada dos institutos Oswaldo Cruz e Butantan. Rio de Janeiro: Editora UFRJ, 1993.

Bezerra, A. F. Atividades de aprendizagem em museus de ciências. Tese (Doutorado em Educação) - Universidade de São Paulo. São Paulo, 2009.

Brazil, V. Relatório do Dr. Vital Brasil. In: Relatório do Instituto Butantan. Arquivo do Instituto Butantan. 1917.

Casazza, I. F. O Jardim Botânico do Rio de Janeiro: um lugar de ciência (1915-1931). Dissertação (Mestrado em História das Ciências e da Saúde) - Casa de Oswaldo Cruz -Fiocruz. Rio de Janeiro: 2011.

Cunningham, A. The culture of gardens. In: Nardine, N. et al. (Eds.). Cultures of Natural History. Cambridge University Press, 1996. p. 38-56.

Dantes, M. A. M. Institutos de pesquisa científica no Brasil. In: Ferri, M. G.; Motoyama, S. História das Ciências no Brasil. São Paulo: EPU, Ed. da Universidade de São Paulo, p. 341-380, 1979-1980.

Dean, W. A ferro e fogo: a história e a devastação da mata atlântica brasileira. São Paulo: Companhia das Letras, 2004.

Dias, C.; Ohtake, R. Jardim da Luz: um museu a céu aberto. São Paulo: Editora Senac São Paulo; Edições Sesc São Paulo, 2011.

Duarte, R. H. A biologia militante: o Museu Nacional, especialização científica, divulgação do conhecimento e práticas políticas no Brasil (1926-1945). Belo Horizonte: Editora UFMG, 2010.

Figueirôa, S. F. de M. As ciências geológicas no Brasil: uma história social e institucional, 1875-1934. São Paulo: Editora Hucitec, 1997.
Florez, L. S. et al. Construção do espaço museal: ciência, educação e sociabilidade na gênese do Parque Zoobotânico do Museu Goeldi (1895-1914). Anais do Museu Paulista, 26, 1-67, 2018. doi: 10.1590/1982-02672018v26e15

Franco, J. L. de A.; Drummond, J. A. Preocupações com a proteção à natureza e com o uso dos recursos naturais na Primeira República brasileira. Textos de história, 12(1/2), 145-165, 2004.

Franco, J. L. de A.; Drummond, J. A. Proteção à natureza e identidade nacional no Brasil, anos 1920-1940. Rio de Janeiro: Editora FIOCRUZ, 2009.

Gualtieri, R. C. E. Ciência e serviço: O Instituto Butantan e a Saúde Pública (São Paulo: 1901-1927). Dissertação (Mestrado em Educação) - Universidade de São Paulo. São Paulo: 1994.

Heizer, A. O jardim botânico de João Barbosa Rodrigues na Exposição Nacional de 1908. Revista de História e Estudos Culturais, 4(3), 1-16, 2007. Disponível em: http://www. revistafenix.pro.br/PDF12/dossie.artigo.7-Alda.Heizer.pdf.

Heizer, A. Notícias sobre uma expedição: Jean Massart e a missão biológica belga ao Brasil, 1922-1923. História, Ciências, Saúde - Manguinhos, 15(3), 849-864, 2008. doi: 10.1590/S0104-59702008000300014

Hingst-Zaher, E.; Teixeira-Costa, L. Raízes do paisagismo no Butantan: o Horto Oswaldo Cruz e a contribuição de F C Hoehne. In: Enokibara, M.; Ghirardello, N.; Salcedo, R. F. B. (Orgs.). Patrimônio, Paisagem e Cidade. Tupã: ANAP, p. 101-127, 2016.

Hoehne, F. C. Relatorio apresentado ao Dr. Vital Brazil. In. Relatório do Instituto Butantan. Arquivo do Instituto Butantan, p. 129-146, 1917.

Hoehne, F. C. Relatório apresentado ao Diretor do Instituto Sôrotherapico de Butantan. In. Relatório do Instituto Butantan. Arquivo do Instituto Butanta, p. 222-241, 1919.

Hoehne, F. C. Relatório anual apresentado ao Director do Instituto Butantan por F. C. Hoehne In. Relatório do Instituto Butantan. Arquivo do Instituto Butantan, p. 70-87, 1920.

Hoehne, F. C. Relatorio da Seç̧ão de Botanica do Museu Paulista referente ao anno de 1924. Arquivo Permanente do Museu Paulista, Fundo Museu Paulista, Livro 8, 1924. 
Hoehne, F. C. Álbum da secção de botânica do Museu Paulista e suas dependências, etc. São Paulo: Imprensa Methodista, 1925a.

Hoehne, F. C. Relatorio da Secção de Botanica do Museu Paulista referente ao anno de 1925. Arquivo Permanente do Museu Paulista, Fundo Museu Paulista, Livro 9, 1925 b.

Hoehne, F. C. Resenha historica para a commemoração do vigesimo anniversario da Secção de Botanica e Agronomia anexxa ao Instituto Biologico de São Paulo. São Paulo: Secretaria da Agricultura, Indústria e Comércio de São Paulo, 1937.

Hoehne, F. C. et al. O. O Jardim Botânico de São Paulo. São Paulo: Secretaria da Agricultura, Indústria e Comércio de São Paulo, 1941.

Hoehne, F. C. Dados autobio-bibliográficos do botanico. In. Hoehne, F. C. Relatório anual do Instituto de Botânica. São Paulo, p. 63-156, 1951.

Hoehne, F. C. Instrucções populares para a colheita, preparo e remessa de plantas para cultura e de amostras vegetaes para identificação scientifica. In. Hoehne, F. C. Publicações. Arquivo do Instituto de Botânica, 3, 153-156. s/d.

Ibañes, N. et al. De Instituto Soroterápico a Centro de Medicina Experimental: institucionalização do Butantan no período de 1920 a 1940. Cadernos de História da Ciência, 2(1), 77-103, 2006. Disponível em: http:// periodicos.ses.sp.bvs.br/scielo.php?script=sci_arttext\&pi$\mathrm{d}=\mathrm{S} 1809-76342006000100004 \& \operatorname{lng}=\mathrm{pt}$.

Instituto Butantan. Cartas recebidas e expedidas. Arquivo do Instituto Butantan. 1917.

Jardine, N.; Spary, E. Introduction. In: Jardine, N. et al. (Eds.). Cultures of Natural History. Cambridge University Press, 1996. p. 3-13.

Luederwaldt, H. O herbário e o horto botânico do Museu Paulista. Revista do Museu Paulista, tomo X, 287-311, 1918.

Machado, D. R. S.; Alves, J. J. de A. A “Atraente Escola de Intuição": o Jardim Zoológico e o Horto Botânico do Museu Paraense de História Natural e Etnografia (1897-1900). In. Lopes, M. M.; Heizer, A. (Orgs.). Colecionismos, práticas de campo e representações. Campina Grande: EDUEPB, p. 207-225, 2011.
Marins, P. C. G.; Schpun, M. R. Introdução - Para além dos trópicos e dos consensos: atores, práticas e questões na história dos parques e jardins no Brasil. Anais do Museu Paulista, 25(3), 9-18, 2017. doi: 10.1590/1982-02672017v25n$03 \mathrm{do}$

Marques, M. E. de A. Jardim Botanico. In: Marques, M. E. de A. Apontamentos históricos, geográficos, biográficos, estatísticos e noticiosos da Província de São Paulo. Tomo II. São Paulo: Livraria Martins Editora S. A., p. 12-13, [1879] 1952.

Molina, A. de A. Frederico Carlos Hoehne (1882-1959) e a flora medicinal brasileira: a pesquisa botânica na cidade de São Paulo no início do século XX. Dissertação (Mestrado em Agronomia) - Universidade Estadual Paulista. Botucatu, 2016.

Molina, A. de A.; Norder, L. A. C. A contribuição de F. C. Hoehne (1882-1959) para o pensamento agroambiental brasileiro. Revista Brasileira de História da Ciência, 7(1), 70-80, 2014.

Oliveira, A. D. de et al. Horto Oswaldo Cruz: histórico e projetos futuros. Cadernos de História da Ciência, 1(1), 82-90, 2005. Disponível em: http://periodicos.ses.sp.bvs.br/scielo.php?script=sci_arttext\&pi$\mathrm{d}=\mathrm{S} 1809-76342005000100007 \& \operatorname{lng}=\mathrm{en} \& \mathrm{t} \operatorname{lng}=\mathrm{pt}$.

Pataca, E. M. Coletar, preparar, remeter, transportar - práticas de História Natural nas Viagens Filosóficas portuguesas (1777-1808). Revista Brasileira de História da Ciência, 4(2), 125-138, 2011. Disponível em: http://www.sbhc.org. $\mathrm{br} /$ revistahistoria/view?ID_REVISTA_HISTORIA $=46$

Raj, K. Relocating Modern Science: circulation and the construction of knowledge in South Asia and Europe, 16501900. Palgrave Macmillan, 2007.

Rocha, Y. T. Dos antigos ao atual Jardim Botânico de São Paulo. Dissertação (Mestrado em Geografia) - Universidade de São Paulo. São Paulo, 1999.

Rocha, Y. T.; Cavalheiro, F. Aspectos históricos do Jardim Botânico de São Paulo. Revista Brasileira de Botânica, 24 (4), 577-586, 2001. doi: 10.1590/S010084042001000500013

Sá, M. R. Um inventário dos sertões brasileiros: a explo- 
ração científica da Comissão Rondon. In: Kury, L; Sá, M. R. (Org.). Rondon: inventários do Brasil. Rio de Janeiro: Andrea Jakobsson Estúdio, p. 110-143, 2017.

Sanjad, N. Nos Jardins de São José: uma história do Jardim Botânico do Grão-Pará, 1796-1873. Dissertação (Mestrado) - Universidade de Campinas. Campinas, 2001.

Sanjad, N. Éden domesticado: a rede luso-brasileira de jardins botânicos (1790-1820). Anais de história de além-mar, (7), 251-278, 2006.

São Paulo. Lei $n^{\circ}$ 1.596, de 29 de dezembro de 1917, "Reorganiza o serviço sanitário do Estado". Disponível em: https://www.al.sp.gov.br/repositorio/legislacao/lei/1917/ lei-1596-29.12.1917.html.

São Paulo. Lei no 1700 de 26 de dezembro de 1919: "Cria, sob a dependencia do Instituto Sorotherapico do Butantan, o Instituto de Medicamentos officiaes". Disponível em: https://www.al.sp.gov.br/repositorio/legislacao/lei/1919/ lei-1700-26.12.1919.html.
São Paulo. Lei ñ . 1.911, de 29 de dezembro de 1922, "Cria no Museu Paulista, a Seção de História Nacional, especialmente de São Paulo, e de Ethnografia". Disponível em: https://www.al.sp.gov.br/norma/66152.

Secretaria do Interior. Relatório apresentado ao Exmo. Snr. Dr. Washington Luis Pereira de Souza pelo secretario do interior Alarico Silveira. Arquivo do Estado de São Paulo, p. 133-134, 1923.

Segawa, H. Ao amor do público: jardins no Brasil. São Paulo: Studio Nobel, FAPESP, 1996.

Silva, A. de F. Entre a implantação e a aclimatação: o cultivo de jardins públicos no Brasil nos séculos XIX e XX. Tese (Doutorado em Arquitetura e Urbanismo) - Universidade de São Paulo. São Paulo, 2016.

Teixeira, A. R. Resenha histórica do Instituto de Botânica de São Paulo. Ciência e Cultura, 40(10), 1045-1054, 1988. 